\title{
Minimally invasive mitral valve repair for degenerative etiology: a comparative study
}

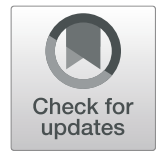

Mohamed Abdel Hafez Fouly ${ }^{1 *}$ (D) and Tarek K. Mousa ${ }^{2}$

\begin{abstract}
Background: There is a paucity of data comparing the minimally invasive mitral valve repair (MiMVr) to the conventional approach in patients with degenerative disease. Our objective was to compare the outcomes of MiMVr to the traditional mitral valve repair through median sternotomy in patients with degenerative mitral valve disease. We conducted a retrospective study on 215 patients classified into two groups. Group $1(n=80)$ included those who had mitral valve repair through a right anterolateral video-assisted mini-thoracotomy, and group 2 ( $n=$ 135) was approached through a conventional median sternotomy. We compared the preoperative, operative, and postoperative data between groups. Both groups had echocardiographic follow-ups after 6 and 12 months.

Results: There was no difference in gender distribution between both groups, and patients who had median sternotomy were significantly older (median 37 (Q1-Q3, 29-44) vs. 54 (48-60) years; $P<0.001$ ). Cardiopulmonary bypass (134.5 (130-138.5) vs. 99 (97-104) min; $P<0.001)$ and ischemic times (99 (95-105.5) vs. 78 (75-81) min; $P<$ 0.001 ) were significantly shorter in patients who had median sternotomy. Patients with MiMVr had significantly lower blood loss (370 (315-390) vs. 550 (490-600) $\mathrm{ml} ; P<0.001)$ and ICU stay (5 (4.5-6) vs. 7 (7-8) days; $P<0.001)$. There was no difference between both groups regarding re-exploration for bleeding, postoperative stroke, wound infection, renal failure, and mortality. As regards postoperative echocardiography follow-up at 6 and 12 months after the operation, there were no significant changes in the mean mitral valve gradient within each group; however, the mean gradient was lower in the MiMVr group (3 (3-3.5) vs. 4 (3-5) $\mathrm{mmHg} ; P<0.001$ ). There was no significant difference between both groups regarding mitral regurgitation severity during 6 and 12 months followup.

Conclusion: Minimally invasive mitral valve repair in patients with degenerative pathology could be an alternative to conventional mitral valve surgery with comparable short-term and long-term outcomes.
\end{abstract}

Keywords: Minimally invasive mitral valve repair, Mitral regurgitation, Hospital outcomes

\section{Background}

Over the last few decades, minimally invasive surgery has transformed surgical practice, including various treatment options in heart surgery [1-4]. Minimally invasive surgery aims to achieve equivalent or better safety and efficacy than traditional surgery, with the added benefits of less trauma, better cosmesis, and shorter hospitalization. In the mid-1990s, videoassisted thoracotomy surgery was first used to do

\footnotetext{
* Correspondence: mhafez1982.gf@gmail.com

${ }^{1}$ Cardiothoracic Surgery Department, Cairo University, Cairo, Egypt

Full list of author information is available at the end of the article
}

minimally invasive mitral valve surgery $[5,6]$. Since then, several significant studies have established the viability of minimally invasive mitral valve repair (MiMVr) at specialist centers for selected patients [7-9].

Patients with symptomatic severe mitral regurgitation with or without impaired left ventricular function are indicated for mitral valve surgery [10]. Additionally, patients with asymptomatic mitral regurgitation but associated with pulmonary hypertension or significant left atrial dilatation could require surgery [10].

\section{Springer Open}

(๑) The Author(s). 2021 Open Access This article is licensed under a Creative Commons Attribution 4.0 International License, which permits use, sharing, adaptation, distribution and reproduction in any medium or format, as long as you give appropriate credit to the original author(s) and the source, provide a link to the Creative Commons licence, and indicate if changes were made. The images or other third party material in this article are included in the article's Creative Commons licence, unless indicated otherwise in a credit line to the material. If material is not included in the article's Creative Commons licence and your intended use is not permitted by statutory regulation or exceeds the permitted use, you will need to obtain permission directly from the copyright holder. To view a copy of this licence, visit http://creativecommons.org/licenses/by/4.0/. 
Despite positive institutional reviews, the MiMVr method had limited implementation. Previous metaanalyses found that minimally invasive mitral valve surgery had better perioperative outcomes than the traditional sternotomy approach. However, few attempts to distinguish repair from replacement procedures and account for the significant variations in the underlying valvular pathology were made [11, 12]. Furthermore, some surgeons are concerned about the mitral valve's limited exposure, arterial damage, and difficulties deairing the heart, all of which could lead to an increase in cerebrovascular accidents [13]. Thus, our objective was to compare the outcomes of MiMVr to the traditional mitral valve repair through median sternotomy in patients with degenerative mitral valve disease.

\section{Methods}

This study was conducted on 215 patients who had mitral valve repair for degenerative disease. Patients had mitral valve repair either through a minimally invasive approach or sternotomy. This study was conducted over 10 years to collect this number of patients with isolated mitral valve disease. Variable techniques for repair were conducted in this study depending on the original pathology including artificial chordae where artificial gortex stitches added from the anterolateral and the posteromedial papillary muscles and sutured to the free edges of both anterior and posterior leaflet to adjust the point of coaptation of both leaflets together preventing mitral regurge or resection of the prolapsed midscallop of the posterior leaflet and placement of a flexible annuloplasty ring. Correction of the anterior leaflet by limited resection, chordal transfer from posterior to anterior leaflet, and, in these cases, replacement of anterior leaflet chordae by polytetrafluoroethylene sutures and also commissural stitches which may complicate later with mitral stenosis associated with increase mean pressure over mitral valve; for all cases, ring annuloplasty were done in addition to the other techniques mentioned before. We included patients who had elective isolated mitral valve repair with normal coronary arteries and no end-organ damage. We excluded patients older than 70 or younger than 16 years with ischemic or rheumatic mitral valve disease and those with infective endocarditis. We also excluded emergency cases and patients with concomitant valve or coronary artery lesions and end-organ failure (stroke, renal, or hepatic failure). The same surgeons performed the operations in both groups with the same technique. Selecting patients to either group was based on surgeons' preference. The study was approved by the local Ethical Committee, and consent to participate was waived because of the retrospective design. The study was conducted according to the Declaration of Helsinki.

The patients were grouped into two groups according to the surgical approach. Group 1 included patients who had MiMVr through a right anterolateral video-assisted mini-thoracotomy, and group 2 had a median sternotomy.

Baseline characteristics of patients were collected, including age, gender, and comorbidities. Intraoperative data included cross-clamp and cardiopulmonary bypass times. Postoperative outcomes were blood loss or need for blood transfusion, ICU stay, sternal wound infection, the occurrence of renal failure or stroke, and hospital mortality.

In addition, patients were followed with echocardiography at 6 and 12 months postoperatively to assess the severity of mitral regurgitation, the mean pressure gradient across the mitral valve, and the need for mitral valve reoperation.

\section{Statistical analysis}

Wilcoxon test was used to compare the quantitative data, which were presented as median and interquartile range. The Chi-square and Fisher exact tests were used to compare the qualitative data, which were presented as frequency and percentages. Linear regression analysis was used to identify factors affecting cross-clamp and cardiopulmonary bypass times. Repeated measure ANOVA was used to test the changes in the mean mitral valve gradient. A random-effect

Table 1 Preoperative and operative data

\begin{tabular}{llll}
\hline & Group $\mathbf{1}(\boldsymbol{n}=\mathbf{8 0})$ & Group 2 (n= 135) & $P$ value \\
\hline Male & $52(65 \%)$ & $80(59.26 \%)$ & 0.40 \\
Age & $37(29-44)$ & $54(48-60)$ & $<0.001$ \\
Hypertension & $20(25 \%)$ & $34(25.19 \%)$ & 0.98 \\
Diabetes mellitus & $32(40 \%)$ & $72(53.33 \%)$ & 0.06 \\
Cross clamp time (min) & $99(95-105.5)$ & $78(75-81)$ & $<0.001$ \\
CPB time (min) & $134.5(130-138.5)$ & $99(97-104)$ & $<0.001$ \\
Mitral repair revision & $6(7.5 \%)$ & $3(2.22 \%)$ & 0.08 \\
\hline
\end{tabular}

(Continuous data were presented as median and interquartile range and qualitative data as frequency and percentage) 
Table 2 Multivariable analysis of factors affecting cardiopulmonary bypass and ischemic times

\begin{tabular}{lll}
\hline & Coef. & $P$ value \\
Cross clamp time & & \\
\hline Age & $-0.03(-0.15-0.08)$ & 0.552 \\
Gender & $0.75(-1.08-2.57)$ & 0.422 \\
Diabetes mellitus & $-0.59(-2.36-1.17)$ & 0.507 \\
Hypertension & $-0.54(-2.57-1.49)$ & 0.600 \\
Group & $-22.19(-24.8--19.58)$ & $<0.001$ \\
Cardiopulmonary bypass time & \\
Age & $-0.08(-0.18-0.03)$ & \\
Gender & $1.16(-0.54-2.87)$ & 0.138 \\
Diabetes mellitus & $-0.97(-2.61-0.68)$ & 0.180 \\
Hypertension & $0.17(-1.72-2.07)$ & 0.248 \\
Group & $-32.61(-35.05--30.17)$ & 0.857 \\
\hline
\end{tabular}

model was used to test the factors affecting the change in mitral valve gradient during follow-up. Stata 16.1 was used to perform the statistical analysis (Stata Corp., College Station, TX, USA).

\section{Results}

\section{Preoperative and operative data}

There was no difference in gender distribution between both groups $(P=0.4)$, and patients who had median sternotomy were significantly older $(P<0.001)$ (Table 1$)$. Cardiopulmonary bypass and ischemic times were significantly shorter in patients who had a median sternotomy. Six patients $(7.5 \%)$ required repair revision in group 1 compare to three $(2.22 \%)$ patients in group $2(P=0.08)$ (Table 1). Surgical approach was the only factor associated with reduced cross-clamp and cardiopulmonary bypass times (Table 2).

\section{Postoperative outcomes}

Patients in group 1 had significantly lower blood loss and hospital stay. There was no difference in re- exploration for bleeding, postoperative stroke, wound infection, renal failure, and mortality between groups (Table 3). After adjusting for the preoperative and operative variables, blood loss did not differ significantly between groups (Table 4). The cause of the mortality in the study was ruptured $\mathrm{A}-\mathrm{V}$ groove which occurred from the presence of annular calcification extending deep in the annulus to the atrioventricular groove and during decalcification of the annulus to create safe area for the mitral ring to be sutured disruption of the A-V groove occurred with severe uncontrolled bleeding. The cause of post-operative mitral stenosis occurred in the post repair of the mitral valve with commissural stitch that complicated with fibrosis and narrowing of the orifice area of mitral valve and so increase the gradient on mitral valve.

\section{Follow-up data}

There were no significant changes in the mean mitral valve gradient at 6 and 12 months within each group $(P=0.1)$; however, the mean gradient is different significantly between both groups $(P<0.001)$ (Fig. 1). Four patients in group 1 had moderate mitral regurgitation at 6 months. Two of them regressed to mild-moderate mitral regurgitation at 1 year, and two progressed to severe mitral regurgitation. Three patients had moderate mitral regurgitation at 6 months in group 2; two of them regressed to mild-moderate $\mathrm{MR}$, and one progressed to severe MR at 1 year. Three patients in group 1 had mitral valve reoperation for severe MR $(n=2)$ and severe MS $(n=1)$ after 1 year; for this patient, commissural stitch was done and so it was complicated with mitral stenosis. One patient in group 2 had mitral valve reoperation for severe $M R$ at 1 year (Table 5). After adjusting the preoperative factors, the group did not affect the change in mitral valve gradient (Table 6).

Table 3 Postoperative outcomes

\begin{tabular}{llll}
\hline & Group 1 $(\boldsymbol{n = 8 0 )}$ & Group 2 (n= 135) & P value \\
\hline Re-exploration for bleeding & $4(5 \%)$ & $10(7.41 \%)$ & 0.58 \\
Blood loss (ml) & $370(315-390)$ & $550(490-600)$ & $<0.001$ \\
Hospital stay (days) & $5(4.5-6)$ & $7(7-8)$ & $<0.001$ \\
Stroke & $2(2.5 \%)$ & $1(0.74 \%)$ & 0.56 \\
Renal failure & $2(2.5 \%)$ & $4(2.96 \%)$ & $>0.99$ \\
Wound infection & & & 0.14 \\
$\quad$ Superficial & $3(3.75 \%)$ & $3(2.22 \%)$ & $>0.99$ \\
$\quad$ Deep & 0 & $6(4.44 \%)$ & $1(0.74 \%)$ \\
Hospital mortality & 0 & & \\
\hline
\end{tabular}

(Continuous data were presented as median and interquartile range and qualitative data as frequency and percentage) 
Table 4 Factors affecting postoperative blood loss

\begin{tabular}{lll}
\hline Blood loss & Coef. & $\boldsymbol{P}$ value \\
\hline Age & $2.58(-3.75-8.9)$ & 0.423 \\
Sex & $33.42(-70.39-137.23)$ & 0.526 \\
Diabetes mellitus & $-33.81(-133.87-66.25)$ & 0.506 \\
Hypertension & $-9.18(-124.13-105.77)$ & 0.875 \\
Group & $214.27(-93.28-521.82)$ & 0.171 \\
Cardiopulmonary bypass time & $0.07(-8.2-8.34)$ & 0.987 \\
\hline
\end{tabular}

\section{Discussion}

Operating on symptomatic mitral regurgitation is increasing and requires refining the surgical techniques to minimize the complications and improve the long-term sequences [14]. Median sternotomy is the standard approach for mitral valve surgery; however, it has suboptimal cosmetic results and the risk of sternal wound infection and long healing time. These factors could affect the return to normal physical activity. Minimally invasive approaches overcome many of these drawbacks [15]. The most common minimally invasive approach is through the right mini-thoracotomy.

In our study, the patients' basic characteristics differed significantly regarding the age where the patients who underwent the MIMVr were younger than those who underwent the conventional approach. Additionally, logistic EuroSCORE was significantly higher in the conventional group, where the average EuroSCORE of this group was 6.8 compared to 3.6 as an average in the group who did MiMVr. This finding reflects our early experience with the minimally invasive approaches in selecting low-risk patients to minimize the complications and improve the learning curve. There was no statistically significant difference in gender, renal function, preoperative rhythm, and EF between groups.

Regarding $\mathrm{CPB}$ and cross-clamp times, it was found that they were more prolonged in the MiMVr group. The average CPB time in the MiMVr group was 134.5 (130-138.5) compared to 99 (97-104) in the conventional group, and the cross-clamp time was 99 (95-105.5) in the MiMVr group compared to 78 (75-81) in the conventional group. These results are concordant with other studies [16], which could be the effect of learning experiences and the setup for the minimally invasive approach.

In addition, the reopening for bleeding and need for blood transfusion was less in patients with MiMVr but with no significant difference. This result is not concordant with other studies [16-18], where the bleeding and need for blood transfusion were statistically less in patients with MiMVr than those with the conventional method. This can be explained by the lower number of patients in each group, and increasing the sample size could make this difference more significant [17].

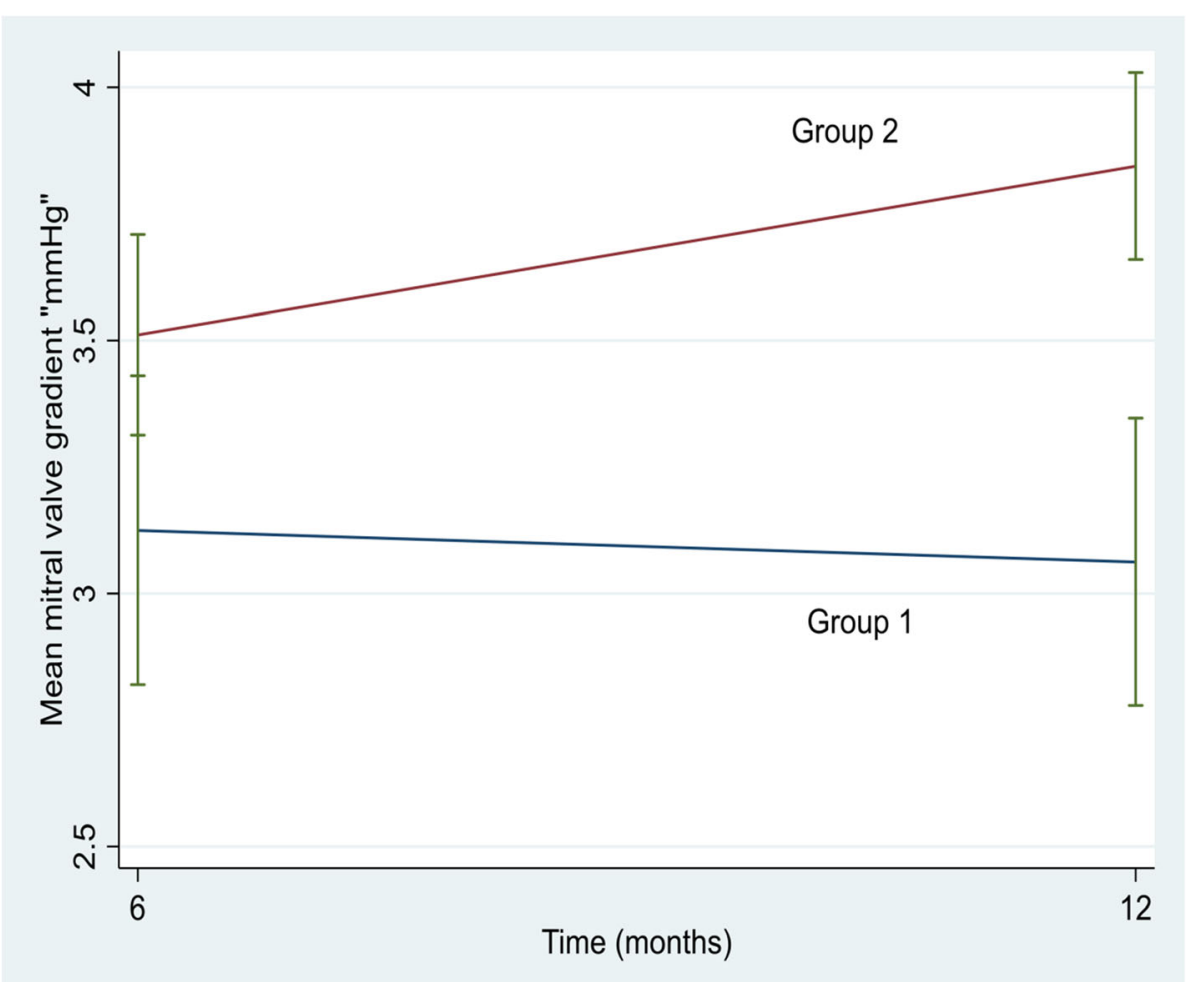

Fig. 1 Change in the mean mitral valve gradient between groups 
Table 5 Follow-up data

\begin{tabular}{llll}
\hline & Group 1 $(\boldsymbol{n}=\mathbf{8 0})$ & Group 2 $(\boldsymbol{n}=\mathbf{1 3 5})$ & $\boldsymbol{P}$ value \\
\hline MV gradient (6months) & $3(2-4)$ & $4(3-4)$ & 0.002 \\
MV gradient (12 months) & $3(3-3.5)$ & $4(3-5)$ & $<0.001$ \\
MR (6 months) & & & 0.43 \\
$\quad$ Moderate & $4(5 \%)$ & $3(2.22 \%)$ & 0.50 \\
MR (12 months) & $2(2.5 \%)$ & $2(1.48 \%)$ & $1(0.74 \%)$ \\
$\quad$ Mild to moderate & $2(2.5 \%)$ & $1(0.74 \%)$ & 0.15 \\
$\quad 3(3.75 \%)$ &
\end{tabular}

(Continuous data were presented as median and interquartile range and qualitative data as frequency and percentage)

$M R$ mitral regurgitation, $M V$ mitral valve

Moreover, the in-hospital mortality did not differ between groups in concordant with Jackson and colleagues' study [19]. Patients in the MiMVr group had lower blood loss and ICU stay, which could improve the long-term outcomes. There was no significant difference in reoperation rate between groups after 1-year follow-up. This result was similar to others [16, 18]. Comparing both groups regarding postoperative echocardiographic findings yielded no significant difference between both groups in recurrence of moderate mitral incompetence and the mean gradient across mitral valve both immediately postoperative and during 1 year follow-up. These results are similar to Christopher and associates' study [1], which showed the same satisfactory echocardiographic outcome in both groups. Still, in Jackson et al.'s study, there was a higher recurrence of moderate mitral incompetence with median sternotomy than those with MiMVr. The mean pressure gradient across the mitral valve in the conventional group increased with a higher value than those with the MiMVr group but was not statistically significant [19].

\section{Study limitations}

The study is limited by the retrospective design and the sample size. Additionally, it is a single-center experience, and generalization of the results may be an issue. The results of the study may be affected by our early experience in minimally invasive approaches as most of complications for minimal invasive approach occurred in the early years of this

Table 6 Factors affecting the change of the mitral valve gradient

\begin{tabular}{lll}
\hline Mitral valve gradient & Coef. & $\boldsymbol{P}$ value \\
\hline Age & $0.01(0.008-0.03)$ & 0.278 \\
Gender & $-0.28(-0.58-0.02)$ & 0.063 \\
Hypertension & $0.14(-0.19-0.47)$ & 0.417 \\
Diabetes mellitus & $-0.04(-0.33-0.25)$ & 0.787 \\
Group & $0.41(-0.02-0.83)$ & 0.061 \\
\hline
\end{tabular}

study; limitations of available data as the baseline echo for all operated cases with baseline gradient across mitral valve and also the detailed technique of repair for each case as this study is carried over 10 years with defect in adequate automated recording of these data in the early years of the study. Surgeon preference is one of the causes of the limitations as most surgeon will chose easy cases that require simple repair technique in minimal invasive cases.

\section{Conclusions}

Minimally invasive mitral valve repair in patients with degenerative etiology is one of the options that can be applied safely depending on the experience and the available set up and can be an alternative to the conventional approach with comparable short and early longterm results.

\section{Abbreviations}

MiMVr: Minimally invasive mitral valve repair; CPB: Cardiopulmonary bypass; ICU: Intensive care unit; MR: Mitral regurge; MS: Mitral stenosis; MV: Mitral valve

\section{Acknowledgements}

None

\section{Authors' contributions}

MF and TK. Both authors have made substantial contributions to the conception and design of the work. Both of them share in the acquisition, analysis, and interpretation of data. Besides, they have drafted the work and substantively revised it. All authors have read and approved the manuscript.

Funding

None

Availability of data and materials

Available upon request

\section{Declarations}

Ethics approval and consent to participate

This study is approved by the Ethical Committee of King Faisal Specialized Hospital and Research Centre, Project number 3320.

For ethics approval, it is available upon request, and for consent to participate is not applicable as it is a retrospective study.

Consent for publication

Not applicable as it is a retrospective study. 


\section{Competing interests}

The authors declare that they have no competing interests.

\section{Author details}

${ }^{1}$ Cardiothoracic Surgery Department, Cairo University, Cairo, Egypt.

${ }^{2}$ Cardiology Department, Ain Shams University, Cairo, Egypt.

Received: 9 July 2021 Accepted: 16 August 2021

Published online: 30 August 2021

\section{References}

1. Cao C, Gupta S, Chandrakumar D et al (2013) A meta-analysis of minimally invasive versus conventional mitral valve repair for patients with degenerative mitral disease. 66:651-658

2. Cosgrove DM, Sabik JF (1996) Minimally invasive approach for aortic valve operations. Ann Thorac Surg 62:596-597

3. Calafiore AM, Angelini GD, Bergsland J et al (1996) Minimally invasive coronary artery bypass grafting. Ann Thorac Surg 62:1545-1548

4. Cao C, Ang SC, Indraratna P et al (2013) Systematic review and metaanalysis of transcatheter aortic valve implantation versus surgical aortic valve replacement for severe aortic stenosis. Ann Cardiothorac Surg 2:10-23

5. Chitwood WR Jr, Wixon CL, Elbeeny JR et al (1997) Videoassisted minimally invasive mitral valve surgery. J Thorac Cardiovasc Surg 114:773-780 discussion 780-2

6. Carpentier A, Loulmet D, Carpentier A et al (1996) Open heart operation under videosurgery and minithoracotomy. First case (mitral valvuloplasty) operated with success. C R Acad Sci III 319:219-223

7. McClure RS, Athanasopoulos LV, McGurk S et al (2013) One thousand minimally invasive mitral valve operations: early outcomes, late outcomes, and echocardiographic follow-up. J Thorac Cardiovasc Surg 145:1199-1206

8. Arcidi JM Jr, Rodriguez E, Elbeery JR et al (2012) Fifteen year experience with minimally invasive approach for reoperations involving the mitral valve. J Thorac Cardiovasc Surg 143:1062-1068

9. Modi P, Rodriguez E, Hargrove WC 3rd et al (2009) Minimally invasive videoassisted mitral valve surgery: a 12-year, center experience in 1178 patients. J Thorac Cardiovasc Surg 137:1481-1487

10. Baumgartner H, Falk V, Bax JJ et al (2017) ESC Scientific Document Group. 2017 ESC/EACTS Guidelines for the management of valvular heart disease. Eur heart 38:2739-2791

11. Cheng DC, Martin J, Lal A et al (2011) Minimally invasive versus conventional open mitral valve surgery: a meta-analysis and systematic review. Innovations (Phila) 6:84103. https:/doi.org/10.1097/MI.0b013e3182167feb

12. Modi P, Hassan A, Chitwood WR Jr (2008) Minimally invasive mitral valve surgery: a systematic review and meta-analysis. Eur J Cardiothorac Surg 34 943-952

13. Mohr FW, Falk V, Diegeler A et al (1998) Minimally invasive port-access mitral valve surgery. J Thorac Cardiovasc Surg 115:567-574 discussion 574-6

14. Gammie JS, Sheng S, Griffith BP et al (2009) Trends in mitral valve surgery in the United States: results from the Society of Thoracic Surgeons Adult Cardiac Surgery Database. Ann Thorac Surg 87:1431-1439

15. Iribarne A, Easterwood R, Chan EY et al (2011) The golden age of minimally invasive cardiothoracic surgery: current and future perspectives. Futur Cardiol 7:333-346

16. Cheng DCH, Martin J, Lal A et al (2016) Minimally invasive versus conventional open mitral valve surgery: a meta-analysis and systematic review. International Society for Minimally Invasive Cardiothoracic Surgery 88:75-91

17. Dokhan AL, Taher AH, Nashy MR et al (2018) Early outcome of thoracoscopic minimally invasive versus conventional mitral valve surgery in mitral valve diseases. Menoufia medical journal 31:1397-1401

18. Grant SW, Hickey GL, Modi P et al (2018) Propensity-matched analysis of minimally invasive approach versus sternotomy for mitral valve surgery. BMJ 105:783-789

19. Manraj J, Sandhu S, Dong C et al (2018) Long-term outcomes comparing minimally invasive mitral valve repair versus conventional mitral valve surgery. World Journal of Cardiovascular Surgery 8. https://doi.org/10.4236/ wjcs.2018.88012

\section{Publisher's Note}

Springer Nature remains neutral with regard to jurisdictional claims in published maps and institutional affiliations.

\section{Submit your manuscript to a SpringerOpen ${ }^{\circ}$ journal and benefit from:}

- Convenient online submission

- Rigorous peer review

- Open access: articles freely available online

High visibility within the field

- Retaining the copyright to your article

Submit your next manuscript at $\boldsymbol{\nabla}$ springeropen.com 